\title{
PROVA DE CONSERVAÇÃO DA QUANTIDADE DE LÍQUIDO: CONCEPÇÕES DE ALUNOS DO QUARTO ANO
}

Stephanie Lee Basile Barboza Caseiro, Kelly Regina Conde, Julia Neves Ferreira, Raul Aragão Martins

Universidade Estadual Paulista - UNESP, Pós-Graduação em Educação, Marília - SP. E-mail: stephanielee 1@hotmail.com.

\begin{abstract}
RESUMO
Jean Piaget foi um importante psicólogo suíço que pesquisou sobre o desenvolvimento da inteligência e da moral na criança. Em seus estudos, desenvolveu uma teoria cognitiva, estabelecendo quatro estágios que caracterizariam o desenvolvimento humano, sendo eles: sensório motor, pré-operatório, operatório concreto e operatório formal. Esta pesquisa teve como objetivo analisar a concepção de 24 alunos de 8 e 9 anos diante de um experimento prático de conservação de quantidade de líquido, comparando os resultados obtidos com as conclusões estabelecidas por Piaget. Espera-se que nessa idade as crianças já se encontrem no estágio operatório concreto, sendo capazes de entender o mundo através do pensamento lógico, utilizando-o para solucionar problemas concretos. Os resultados indicaram que os alunos avaliados são capazes de conservar a quantidade de líquido.
\end{abstract}

PALAVRAS-CHAVE: Jean Piaget, epistemologia genética, conservação de quantidade, desenvolvimento humano, teoria cognitiva.

\section{PROOF OF CONSERVATION OF THE LIQUID'S AMOUNT: CONCEPTIONS OF FOURTH YEAR STUDENTS}

\begin{abstract}
Jean Piaget was an important swiss psychologist who researched the development of intelligence and moral in children. In his studies, he developed a cognitive theory, establishing four stages that would characterize human development, being: motor sensory, preoperative, concrete operative and formal operative. This research had the objective of analyzing the conception of 24 students of 8 and 9 years in a practical experiment of conservation of liquid's amount, comparing the results obtained with the conclusions established by Piaget. It is hoped that at this age the children will already be in the concrete operative stage, being able to understand the world through logical thinking, using it to solve concrete problems. The results indicated that the evaluated students are able to conserve the amount of liquid.
\end{abstract}

KEY WORDS: Jean Piaget, genetic epistemology, quantity conservation, human development, cognitive theory. 


\section{INTRODUÇÃO}

Jean Piaget, importante teórico da psicologia do desenvolvimento, buscou em seus estudos a origem do conhecimento - com sua chamada epistemologia genética. $O$ autor explicou 0 desenvolvimento cognitivo e afetivo com raízes nas ações impulsionadas por um motivo, o que se traduz como uma necessidade provocada por uma situação de desequilíbrio (PIAGET, 1991 [1964]).

Nesta perspectiva, cabe observarmos as noções de esquema, assimilação e acomodação:

Os Esquemas são estruturas mentais referentes a um todo organizado, estando relacionados com uma estrutura cognitiva específica. A Assimilação concerne à capacidade de o sujeito incorporar objetos da cognição à sua estrutura cognitiva. A Acomodação concerne ao reajustamento ocorrido na estrutura de modo a poder incorporar o novo objeto. $O$ equilíbrio entre a assimilação e a acomodação recebe o nome de equilibração. Em todo processo de interação do sujeito com o objeto, os processos de Assimilação e Acomodação se encontram presentes, ora com a predominância de um, ora com a predominância de outro. Os esquemas possuem uma plasticidade dinâmica, adaptando-se à realidade de maneira a poder assimilá-la. Diante de uma situação externa, ocorre a aplicação do esquema, isto é, a ação assimiladora do sujeito inicia um ciclo de ações sobre o objeto. Se o esquema conseguir incorporar o novo objeto à estrutura previamente existente ocorre a manutenção da situação atual. Mas se o esquema não conseguir incorporar o novo objeto frente ao qual o sujeito se encontra, então o sujeito está diante de um desequilíbrio (CORRÊA, 2017, p. 380).

Piaget considera o processo de equilibração como a fonte real do progresso pois os desequilíbrios obrigam os sujeitos a sair de suas condições atuais buscando novas direções. Em outras palavras, no processo de interação vivenciados, podem ocorrer desajustes que rompem como estado de equilíbrio do indivíduo, que recorre a diferentes alternativas para se reestabelecer. Isso ocorre devido aos processos contínuos de assimilação e acomodação, considerados por Borges e Fagundes (2016) como complementares e indissociáveis.

Dessa forma, a assimilação tem a função de incorporar elementos exteriores aos esquemas sensórios motores do sujeito, enquanto a acomodação é responsável por criar ou alterar esquemas de assimilação já existentes. "A assimilação permite, por exemplo, a identificação de propriedades de objetos a fim de organizá-los em classes. O processo de acomodação é o responsável pela incorporação dessas classes ao sistema conceitual do sujeito" (BORGES; FAGUNDES, 2016, p.246)

Portanto, é importante ressaltar que para que a criança avance em seu desenvolvimento, é necessário que o ambiente promova as condições necessárias para que as transformações cognitivas ocorram, possibilitando que ela vivencie situações em que se estabeleça um conflito cognitivo que demanda um esforço para superá-lo, a fim de que o equilíbrio seja reestabelecido.

Terra (s.d) elucida que quando consideramos a construção das competências cognitivas, podemos dizer que a função do objeto é desequilibrar o sujeito e, quando o sujeito não consegue assimilar o objeto, busca a tomada de consciência, regulando e variando suas ações em função do resultado desejado.

Nas palavras de Piaget, "O desenvolvimento, portanto, é uma equilibração progressiva, uma passagem contínua de um estado de menor equilíbrio para um estado de equilíbrio superior" (PIAGET, 1991, p. 11). Seus estudos baseavam-se em observações detalhadas das experiências vivenciadas pelas crianças e diálogos com as mesmas. Dessa forma, além de observar, interagir e questionar as crianças, Piaget também realizou entrevistas clínicas visando investigar o que as concepções infantis sobre diversos temas.

O método clínico piagetiano é assim denominado por visar ir além da resposta estereotipada para compreender o ponto de vista do sujeito entrevistado. Em uma conversa aberta com o sujeito sobre um determinado tema, o pesquisador intervém de forma sistemática conduzindo suas perguntas para o esclarecimento das ideias do indivíduo. Porém, é importante 
destacar que tal método não se isenta de inconvenientes, sendo necessário um aprofundado conhecimento da teoria para que seja possível colocá-lo em prática. Queiroz e Lima (2010, p. 117) ressaltam que "o bom pesquisador precisa reunir duas qualidades frequentemente incompatíveis: saber observar, deixar a criança falar, nunca interromper nem lhe desviar a atenção e, ao mesmo tempo, saber procurar algo".

Por meio da observação do desenvolvimento das crianças, Piaget desenvolveu a Teoria cognitiva, propondo quatro estágios no desenvolvimento humano, caracterizados pelos avanços do indivíduo nas diferentes faixas etárias ao longo de seu desenvolvimento. São eles: sensóriomotor ( 0 a 2 anos- entende o mundo através das sensações e movimentos: desenvolvimento da coordenação motora em que o bebê percebe que seus movimentos geram ações), pré-operatório (2 a 7 anos - entende o mundo através da linguagem e imagens mentais: surgimento do egocentrismo e pensamento baseado em experiências individuais), operatório concreto (7 a 11 anos - entende o mundo através do pensamento lógico, utilizando-o para solucionar problemas concretos) e operatório formal (aquisição do raciocínio lógico pela criança que já é capaz de criar situações hipotéticas e desenvolver possibilidades). Com a entrevista clínica é possível visualizarmos de forma prática tais estágios, ressaltando como as características de cada nível influenciam o desenvolvimento intelectual e moral da criança (MENESTRINA et al, 2014).

Cada um dos estágios possui características e estruturas próprias de funcionamento, caracterizados por diferentes formas de organização mental, dependentes do estágio anterior. A partir de então, se organizam novas estruturas que levam a um estágio mais complexo. Terra (s.d) ressalta que de um forma geral todos os indivíduos vivenciam as 4 fases na sequência, mas o início e o término de cada uma pode sofrer variações em função das características e dos estímulos proporcionados pelo ambiente no qual ele está inserido.

Dessa forma, temos como objetivo neste estudo a análise de uma experiência de conservação de quantidade de líquido realizada com alunos do quarto ano do Ensino Fundamental I, visando identificar as percepções dos alunos diante do experimento realizado, considerando a expectativa de que todos os participantes, de acordo com a idade, encontram-se no nível operatório concreto.

\section{METODOLOGIA}

A pesquisa consiste em analisar as concepções de alunos da quarta série do ensino fundamental I sobre a conservação de líquidos, partindo de respostas dadas pelos estudantes em uma avaliação escolar. Ressaltamos que o conceito de conservação de quantidade de líquido foi analisado em estudos teóricos, dentro da sala de aula e práticos, em laboratório.

Segundo a teoria piagetiana, quando a criança está passando pelo período operatório concreto, ela tem noção de conservação, isto é, a criança é capaz de conservar mentalmente (lembrar-se de) uma dada quantidade, embora observe modificações na aparência do objeto ou da substância.

Cabe ressaltar que esta pesquisa foi previamente avaliada e aprovada pelo Comitê de Ética em Pesquisa (CEP), com o protocolo CAAE de no 69610017.5.0000.5406.

\section{PARTICIPANTES E PROCEDIMENTO}

A presente pesquisa contou com a participação de vinte e quatro (24) estudantes de uma escola da rede particular de ensino de São José do Rio Preto, do quarto ano do Ensino Fundamental I, que compreende crianças de oito a nove anos. A instituição em que a avaliação foi realizada oferece as três etapas de ensino da educação básica e ainda disponibiliza aulas de laboratório de ciências, no qual são realizados experimentos de acordo com as teorias estudadas previamente em sala de aula. 
O conceito apresentado aos participantes desta pesquisa foi sobre a conservação da quantidade de líquido, segundo o qual se debruçou o estudioso Jean Piaget. Em suas análises, Piaget denominou o experimento que avalia tal conceito como prova de conservação da quantidade de líquidos. Após explicações teóricas dentro da sala de aula sobre o assunto, os alunos puderam desfrutar da experiência prática dentro do laboratório, descrita a seguir:

1. Pega-se dois grandes béqueres contendo líquido;

2. O professor faz a criança verificar que os dois béqueres contêm a mesma quantidade de líquido;

3. Depois, à medida que a criança observa, o professor despeja o líquido de um dos béqueres em outros dois béqueres, que são menores do que os outros dois;

4. Em seguida, questiona-se em qual há maior quantidade de líquido: nos dois béqueres menores ou no béquer maior.

Para confirmação da compreensão, durante as avaliações mensais, foi elaborada uma questão sobre o assunto, como mostra a figura abaixo:

Figura 1. Questão da avaliação escolar

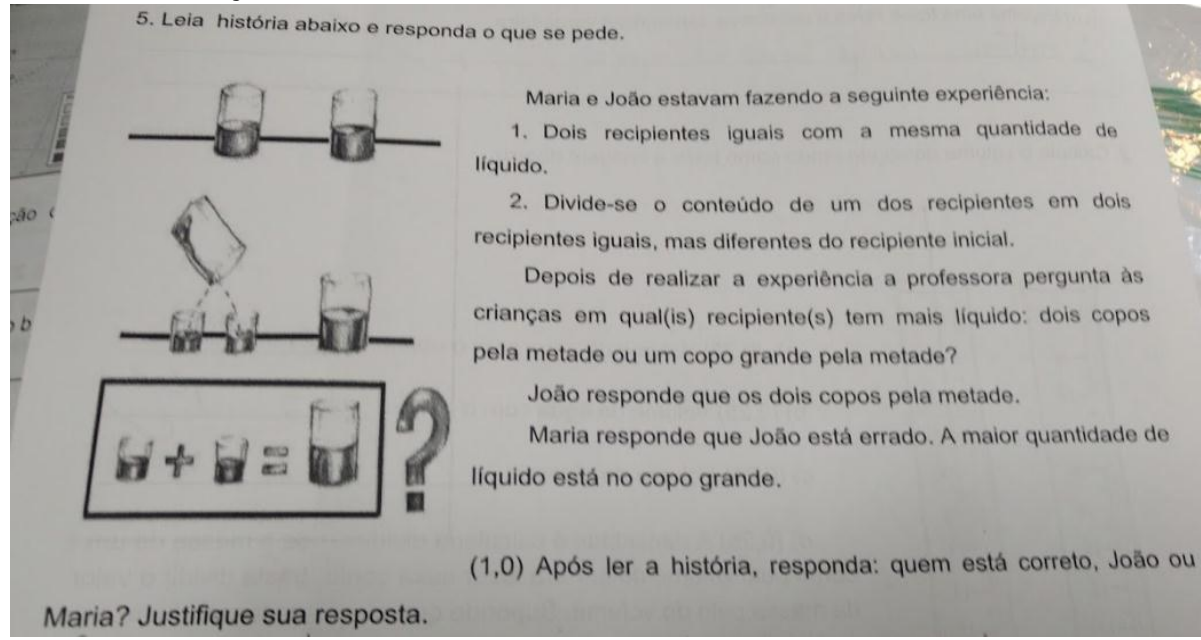

Nesta questão avaliativa de número cinco, além de descrever o ocorrido, é colocada também uma imagem que mostra a experiência. Nesta avaliação, é relatado que João e Maria estavam fazendo este experimento e que ao serem questionados em quais recipientes tem mais líquido (dois copos pela metade ou um copo grande pela metade), João responde que os dois copos pela metade e Maria defende que a maior quantidade de líquido está no copo grande. Então, pergunta-se ao aluno quem está correto, João ou Maria.

\section{RESULTADOS}

Dos vinte e quatro alunos, seis responderam que foi João o correto (25\%), cinco optaram pela resposta de Maria (20,83\%), onze por nenhum dos dois $(45,83 \%)$, um colocou que os dois estão corretos $(4,16 \%)$ e apenas um aluno deixou a resposta em branco $(4,16 \%)$.

Vale ressaltar que os seis alunos que escreveram que João está correto, mesmo sendo a resposta errada, deram como justificativa uma resposta correta, como exemplo: "João, pois se está em copos menores, se juntar de novo vai ficar pela metade". Já os alunos que compreenderam que Maria era quem estava certa, mesmo sendo também a resposta errada, as justificativas foram dadas como a seguir: "Maria, porque o copo grande tem a metade dos deles", "Maria, porque dois copos pela metade dá um copo e um copo mais um copo dá dois copos que tem mais água" e "Maria, porque a maior quantidade está no copo maior".

As respostas nas quais foram colocadas que os dois estão corretos ou nenhum dos dois acertaram, foram de praticamente cinquenta por cento dos alunos, ou seja, metade da turma. 
Esses estudantes compreendem que tanto dois copos pequenos quanto um copo grande pela metade têm a mesma quantidade de líquido, isto é, realizaram adequadamente a prova da conservação dos líquidos. Foram encontradas respostas tais como: "Nenhum dos dois, pois tem a mesma quantidade", "Nenhum, pois o que muda é apenas o tamanho do copo e não a quantidade de líquido", "Nenhum, dois copos pequenos é um grande" e "Os dois, porque se juntar os dois copinhos dá o copo grande".

Apenas um aluno deixou a questão sem resposta, e, ao ser questionado sobre o motivo, justificou que não entendeu muito bem o que deveria fazer.

\section{DISCUSSÃO}

Em geral, os alunos avaliados são capazes de conservar a quantidade de líquidos. Dado interessante é que uma quantidade expressiva de alunos, apesar de conservar a quantidade, não respondeu adequadamente à questão, dizendo que um ou outro dos personagens estava certo sobre sua afirmação, quando na verdade ambos estavam errados. Isso, no entanto, denuncia maior dificuldade com interpretação de textos do que com a construção da noção de quantidade, que pudemos notar estar adequada.

Ainda temos que um aluno não foi capaz de responder à questão adequadamente e nem de justificá-la corretamente. Uma resposta dizia que quem estava correta na história era "Maria, porque a maior quantidade está no copo maior". Não há menção, nesta resposta, à equivalência entre o copo maior e os dois menores, mostrando que não há noção da conservação. No entanto, consideramos o resultado inexpressivo, por não podermos descartar completamente a possibilidade de dificuldade na interpretação da questão e por haver apenas uma resposta deste tipo na avaliação $(4,16 \%)$.

\section{CONCLUSÃO}

Podemos perceber, como previa Piaget, que os alunos avaliados são capazes de conservar a quantidade de líquidos. Dada a sua idade (entre 8 e 9 anos), é esperado que vejam o mundo por meio do pensamento lógico, e consigam utilizá-lo para solucionar problemas.

No estágio operatório concreto, no qual se encontram os participantes desta pesquisa, embora a criança ainda se oriente por referências concretas e reais para a formulação do seu pensamento, ela tem a habilidade para a conservação, sendo capaz de identificar os processos de transformações ocorrentes.

Concluímos que, neste estágio em que se encontram os sujeitos analisados, as estruturas que permitem a conservação de quantidades já estão estabelecidas e, portanto, estas crianças não apresentam dificuldade em perceber que a mudança de formato ou tamanho de dado recipiente não alteram a quantidade de líquido em seu interior, como constatamos.

\section{REFERÊNCIAS}

BORGES, K. S.; FAGUNDES, L. C. A teoria de Jean Piaget como princípio para o desenvolvimento das inovações. Revista Educação. Porto Alegre, v. 39, n. 2, p. 242-248, maio-ago. 2016

CORRÊA, C. R. G. L. A relação entre desenvolvimento humano e aprendizagem: perspectivas teóricas. Psicologia Escolar e Educacional, SP. Volume 21, Número 3, Setembro/Dezembro de 2017, p. 379-386.

MENESTRINA, T. C. Análise piagetiana do desenvolvimento cognitivo: experiências com crianças do ensino fundamental. ISSN 1982-4866. Revista Dynamis. FURB, Blumenau, v. 20, n. 1, p.54-73, 2014

PIAGET, J. Seis estudos de psicologia. Tradução: Maria Alice Magalhães D’Amorim e Paulo Sérgio Lima Silva. 18ạ Edição. Rio de Janeiro: Forense Universitária, 1991 [1964]. 
QUEIROZ, K. J. M.; LIMA, V. A. A. Método clínico piagetiano nos estudos sobre Psicologia Moral: o uso de dilemas. Revista Schème Volume 3 Número 5 - Jan-Jul/2010, p.110-131

TERRA, M. R. O desenvolvimento humano na teoria de Piaget. Disponível em: <https://www.unicamp.br/iel/site/alunos/publicacoes/textos/d00005.htm\#_ftn1>. Acesso em: 30 jul. 2018. 